\title{
A Study on AIDS Prevention and Treatment Education in China's Colleges and Universities under the Government-Purchase-Service Mode
}

\author{
Tao WU \\ Department of Health Management \\ Xi' an Medical University \\ Xi'an, China
}

\begin{abstract}
AIDS is one of the major infectious diseases in China, hence the publicity of its prevention and treatment has been continuously increasing. With the rapid development of China's economy, the government must provide more extensive and effective service to the public. In respect of AIDS prevention and treatment, the effective intervention of government functional departments has played a role, and all major colleges and universities have always attached great importance and vigilance to the prevention and treatment of AIDS. Although China's colleges and universities have not only improved their understanding and knowledge of AIDS but also changed their concepts, their popularization of AIDS-related knowledge is still far from enough, and their AIDS prevention and treatment is not satisfactorily effective. This study takes AIDS prevention and treatment as the entry point, and introduces the governmentpurchase-service mode, its existing problems and corresponding solutions. It also discusses the status quo of AIDS prevention and treatment in China's colleges and universities under the government-purchase-service mode, and proposes some solutions so as to effectively curb the incidence of AIDS in colleges and universities so as to contribute to AIDS prevention and treatment in China.
\end{abstract}

Keywords-government-purchase-service mode; colleges and universities; AIDS prevention and treatment; Students;

\section{INTRODUCTION}

Public health has always been a service that is closely related to public life. With the support of international funds, many social forces have participated in it, effectively promoting the role of social organizations in AIDS prevention and treatment. From 2011, international fund programs started to withdraw from China, and the 2012-2013 Community Organization Participation Program of Global Fund AIDS Program was the last global fund program in China [1]. Since then, China's anti-AIDS fund has decreased drastically. In this context, the Chinese government needs to fill the money void. Our experience of AIDS prevention and treatment indicates that social organizations play a huge role in the prevention and treatment of AIDS [2].

Funded by: 2015 Xi'an Medical University Start-up Fund Program for PhDs (NO. 2015DOC26; Name: An Explorative Study on the New Model for AIDS Intervention among College Students)
Therefore, the mode of government purchasing service from social organizations has become the new approach to AIDS prevention and treatment in China, supporting social organizations to continue their irreplaceable role. Under such a mode, colleges and universities are in proactive cooperation with the government in the fight against AIDS, creating a healthy learning and living environment for teachers and students. Although China's colleges and universities have always adhered to the principle of prevention first and treatment as supplementary, there are still shortcomings in some aspects.

As the quality of AIDS-related work is related to the health of college teachers and students, it must be highly valued. This paper reviews the developments of AIDS prevention and treatment in China's colleges and universities under the government-purchase-service mode, and provides some reference in this regard [3].

\section{A REVIEW OF THE GOVERNMENT-PURCHASE- SERVICE MODE AND ITS EXISTING PROBLEMS}

\section{A. A Review of the Government-purchase-service Mode}

Directly providing public health service to AIDS patients, high-risk groups, their family members and the general public, social organizations have more advantages than the government in AIDS prevention [3]. As AIDS patients pay great attention to privacy, the government is often faced with such problems as inability to locate the patients and strong psychological resistance. However, social organizations are different: their employees share similar experiences and conditions with the target groups, resonance and recognition are easily generated, and then health education, care, rescue, visits and other efforts on AIDS prevention and treatment can be smoothly carried out [4].

With the continuous development, more and more qualified social organizations have participated in the competition for the service purchased by the government. There are 3 modes for the government to purchase the service of AIDS prevention and treatment from social organizations.

The first one is non-competitive authorized or entrusted purchase [5]: the purchase of service, based on the needs of the 
purchaser, allows the experts to directly select a social organization after their evaluation rather than through successful bidding. This mode is highly efficient, enabling the purchase of service after a short period of time; its downside is that competitive bidding has to be conducted if the financial fund exceeds a certain amount.

The second mode is purchase after competitive bidding which is the main purchase mode: according to the objective of a service project, the organizer initiates the bidding process, willing social organizations fill out the application form, and then qualified social organization(s) are chosen to complete the project [6]. This mode involves continuous activities necessary for the project: test and intervention for high-risk groups and care for AIDS patients.

In terms of the evaluation mechanism, the purchase through competitive bidding can be divided into result-oriented marketized purchase and the planned purchase that regard activities as output. As the most appropriate mode for the government to purchase service, purchase after competitive bidding selects competent social organizations from the competition to carry out anti-AIDS work.

The third mode is non-competitive subsidized purchase [7]: social organizations are given a certain amount of financial subsidy to subsist. This mode solves the survival problem of social organizations, but the small amount of fund does not fundamentally solve the problem of sustainable development of social organizations.

\section{B. Problems for the Government-purchase-service Mode}

The first problem is the faulty mechanism for governmentpurchase-service mode. In 2013, the activities of large international programs for AIDS prevention and treatment in China came to an end. Since then, the Chinese government has become the purchaser of social service, but its operations and effective use of financial fund are still under discussion [8]. The second problem is that the local governments are weak in their willingness to purchase anti-AIDS service from social organizations [9].

According to the survey, although some governments in some economically-developed cities actively purchase service from social organizations, most local governments fail to do so. The third problem is the survival of social organizations. Social organizations launch activities on funds, but the current funds merely cover labor costs and there are no funds for human resources [10].

In the 21 st century when commodity prices are on the continual rise, service costs have increased significantly and now survival is the biggest challenge [11]. Other than that, the government is striving to showcase the registration of social organizations as its achievements, but the organizations are not interested because registration indicates more operating costs and more survival difficulties [11].

\section{Solutions for the Government-purchase-service Mode}

First, in the face of a dilemma after the international programs have withdrawn, the Chinese government can purchase large-capital service projects through competitive bidding. Where the AIDS prevention and treatment funds are limited, the disease control department can resort to noncompetitive authorized or entrusted purchase as a way to reduce costs. Besides, the local disease control department should consider the costs of purchasing anti-AIDS service from social organizations when applying for the financial budget in case of fund shortage [12].

Secondly, while the local government has responded to the national policies, AIDS prevention and treatment projects are not effectively included into the services to be purchased by the government. To address this issue, the government should encourage unregistered grassroots social organizations to apply for service projects, promptly inform major social organizations of the information on the AIDS prevention and treatment work carried out by international organizations in China, and do its utmost to help these social organizations with funds [13].

Thirdly, the willingness of local governments to purchase service from social organizations can be enhanced through policy advocacy. The health administration can establish a mechanism to purchase social service from grassroots organizations with integrity and give play to their advantages. As for pricing, it should correspond to specific areas in China [14].

\section{THE STATUS QUO OF AIDS PREVENTION AND TREATMENT IN CHINA'S COLLEGES AND UNIVERSITIES UNDER THE GOVERNMENT- PURCHASE-SERVICE MODE}

In 2014, the number of AIDS patients aged 15-24 in China was 15,000 in 2014, an increase of $20 \%$ from 2013; among them, 2552 were students, an increase of 59\% from 2013 [15]. In 2015, the number of AIDS patients aged 15-24 was around 75,000 , growing at quite a fast rate [16].

Additionally, the infection rate among young males has also been rising. In the 12th five-year action plan on AIDS prevention and treatment, it was proposed that over $90 \%$ of young adults and teenagers should have knowledge of AIDS prevention and treatment by the end of 2015 [17]. At present, more than $90 \%$ of Chinese college students have basic knowledge of AIDS, but they fail to know about the professional knowledge and correct approaches to AIDS prevention [18].

At the age associated with a high AIDS infection rate, college students are the focus of AIDS prevention and treatment, being the country's concern and care. There are two reasons for this: the first is that college students are in adolescence, physically and psychologically being at the risk of AIDS; the second is that, in the era of diverse cultures and various thoughts from both China and the West, more and more of Chinese college students no longer insist on traditional moral values, becoming more open about gender relations [19].

However, in stark contrast to the openness, these college students do not understand AIDS-related knowledge very comprehensively: they don't know well whether AIDS can be cured and how it is transmitted, and their attitude and behaviors towards AIDS patients are also not positive. Both the lack of 
publicity of AIDS-related knowledge and the lack of education on healthy behaviors have determined that college students are at high risk of AIDS. As the situation is gravely serious, it is extremely urgent to carry out effective anti-AIDS work in colleges and universities. [20]

\section{EFFECTIVE MEASURES FOR AIDS PREVENTION AND TREATMENT IN CHINA'S COLLEGES AND UNIVERSITIES UNDER THE GOVERNMENT- PURCHASE-SERVICE MODE}

\section{A. To Establish the Government-purchase-service System}

As the key component to purchase public service from social organizations, the Chinese government has not launched well-rounded policies. The state council, financial sector and civil affairs departments are still at the level of offering guidance and suggestions. Service purchase by local governments has not been put into practice [21]. In this context, the government should establish a guidance system as soon as possible to clarify the scope, mode, and social organization qualifications of the service purchased by the government, and determine the health service that the public needs.

The government should also incorporate the service into the budget, institutionalize the purchase, and improve the management of service purchase. Moreover, it is necessary to give play to the government's advantages in official publicity and education of AIDS prevention so as to remove public discrimination against AIDS and enhance public understanding of AIDS-related knowledge [22].

\section{B. To Carry out Both In-class and After-class activities}

In view of the lack of health knowledge among students, China's colleges and universities can effectively strengthen AIDS education in their quality-oriented education through both open courses and regular courses on general AIDS-related knowledge and AIDS prevention and treatment [23]. On the World Health Day, World AIDS Day, World Blood Donor Day and International Day against Drug Abuse and Illicit Trafficking, various specialized activities on AIDS prevention can also be carried out, such as exhibitions, knowledge contests, volunteer service and on-campus signing events.

In this way, college students can participate and develop interest in AIDS-related knowledge. In addition, some books on AIDS prevention can be placed in the library for them to read. All above can help Chinese college students prevent AIDS to a certain degree.

\section{CONCLUSION/SUMMARY}

To sum up, colleges and universities are the publicity focus of AIDS prevention and treatment, and their prevention and treatment work is closely related to AIDS prevention across China. The government-purchase-service mode has mobilized more personnel to participate, and college students are one of its beneficiaries. The mode has assisted in AIDS prevention, raised the public satisfaction towards the government, and helped create a harmonious and healthy social atmosphere.

\section{REFERENCES}

[1] Y. Zheng, etc., The impact of China Global Fund AIDS program on the development of MSM community organizations[J], Chinese Journal of Disease Control \& Prevention, 2015,19(12):1265-1268.(In Chinese).

[2] J. Xue, etc., Analysis on AIDS prevention and control work of Chinese social organizations 2012 - 2014[J], Chinese Journal of Public Health, 2018,34(03):428-431.(In Chinese).

[3] Z. Zhoum etc., An exemplary study on AIDS prevention education in Colleges and universities [J], Chinese University Science \& Technology, 2017(S1):75..(In Chinese).

[4] J. Li, etc., Performance indicators for the evaluation of social organizations' participation in AIDS prevention and control [J], Chinese Journal of AIDS \& STD, 2017,23(04): 303-306.(In Chinese).

[5] Y. Wang, etc., Research on the main problems and solutions of the government's purchase of AIDS prevention and control services [J], Chinese Journal of Public Health Management, 2018,34(01):1-4.(In Chinese).

[6] M. Li, etc., Yunnan's social organizations participating in AIDS prevention and control analysis under the background of government purchasing services [J], Soft Science of Health, 2016,30(12):3-6+16.(In Chinese).

[7] G. Zheng, etc.,Exploration of government purchasing social organization services in AIDS prevention and treatment [J], Chinese Rural Health Service Administration, 2015,35(01):53-55.(In Chinese).

[8] Z. Leng, etc., Problems and suggestions on Chinese government's purchase of social organizations in the field of AIDS prevention and control [J], Chinese Health Economics, 2017,33(10):55-57.(In Chinese).

[9] M. Huang, etc., Guangyuan City Lizhou district "1+8+N" to promote social organizations to participate in anti AIDS work mode to explore [J] Journal of Occupational Health and Damage, 2018,33(02):123-125.(In Chinese).

[10] J. Dai, etc., Investigation of AIDS prevention and control social organizations in Qujing City $[\mathrm{J}]$, Soft Science of Health, 2015,29(02):117-121.(In Chinese).

[11] J. Liu et Y. Zou, Analysis of government purchase of social services in the field of AIDS prevention and control [J], Soft Science of Health, 2013,27(05):261-263.(In Chinese).

[12] H. Liang, etc., Reflection on promoting the participation of civil society organizations in AIDS prevention and control from the perspective of micro social capital [J], Chinese Health Service Management, 2015,32(01):74-76 .(In Chinese).

[13] H. Cheng and Y. Du, Investigation and analysis of AIDS prevention and control by social organizations in Jiangxi province [J], Chinese Journal of Disease Control \& Prevention, 2014,18(12):1209-1212.(In Chinese).

[14] C. Lv, etc., Cognition and evaluation of social organizations participating in AIDS prevention and control by government departments and professional staff members [J], 2015,21(11):99.(In Chinese).

[15] L. Yang, etc., Discussion on AIDS prevention and control work in Colleges and universities [J], Health Education and Health Promotion, 2015,10(05):398-400.(In Chinese).

[16] J. Zhang, Strategies for AIDS prevention and control among young students [J], Chinese Journal of School Health, 2016,37(11):16011603.(In Chinese).

[17] Y. Tang, etc., Analysis on the current situation and preventive measures of AIDS infection among university students [J], Chinese Health Service Management, 2017,34(06):474-476.(In Chinese).

[18] Y. Lv, Explore how to carry out AIDS health education among university students [J], Chinese Journal of Urban and Rural Hygiene, 2018,33(08):13-16.(In Chinese).

[19] H. Si, etc., Research progress of peer education on AIDS among university students [J], Chinese Evidence-Based Nursing, 2017,3(05):464-468.(In Chinese).

[20] J. Mu and W. Song, Analysis of AIDS epidemic among students in Shenyang City in 2007-2016 [J], Modern Preventive Medicine, 2018,45(08):1504-1507.(In Chinese). 
[21] W. Deng, The dilemma and optimization of government purchasing social services from the perspective of public nature $[\mathrm{J}]$, Journal of Chongqing University(Social Science Edition), 2016,22(01):203-208.(In Chinese).
[22] J. Yi, Challenges and Countermeasures for AIDS prevention and control in Colleges and universities [J], Chinese Journal of School Doctor, 2017,31(06):405-406+409.(In Chinese).

[23] X. Wang, etc., Problems and Countermeasures of AIDS health education in local colleges and universities [J], Chinese Journal of School Doctor,2017,31(04):262-263.(In Chinese). 